\title{
A rare cause of chronic lymphadenopathy with pancytopenia in an infant
}

\author{
Jagdish Ashok Kathwate ${ }^{1}$, V Sumitra ${ }^{1}$, K Shilpa ${ }^{1}$, S S Prabhu ${ }^{1}$
}

Sri Lanka Journal of Child Health, 2014; 43(4): 234-236

(Key words: Cytopenia; lymphadenopathy; autoimmune lymphoproliferative syndrome; double negative T cells)

\section{Introduction}

Autoimmune lymphoproliferative syndrome (ALPS) is the first human disease whose aetiology has been attributed to a primary defect in apoptosis or programmed cell death. ALPS is a rare disorder in children characterized by splenomegaly, massive lymphadenopathy, autoimmune phenomena such as thrombocytopenia, neutropenia, haemolytic anemia and accumulation of double-negative (CD3+CD4CD8-) $\mathrm{T}$ cells in the blood ${ }^{1,2}$. In the majority of patients ALPS occurs due to inherited mutations in genes encoding proteins of the Fas pathway, which mediates programmed cell death or apoptosis ${ }^{3}$.

\section{Case report}

A one year old boy presented with hepatosplenomegaly, anaemia and neutropenia. His complaints began at seven months of age and were gradually progressive. He was born of a thirddegree consanguineous marriage. Physical examination revealed pallor, significant cervical lymphadenopathy, firm hepatomegaly of $2 \mathrm{~cm}$ and a spleen of $3 \mathrm{~cm}$. Developmental status and other systemic examinations were normal. His blood count showed a hypochromic, microcytic anaemia (hemoglobin level of $7 \mathrm{~g} / \mathrm{dl}$ ), thrombocytopenia (platelet count of $19,000 / \mu \mathrm{l}$ ) and neutropenia (white blood cell count of $5,500 / \mu 1$ with an absolute neutrophil count of 330), thus indicating pancytopenia. The liver function tests, lipid profile and serum immunoglobulin levels were unremarkable and tuberculin test was negative. Direct and indirect Coombs tests were negative. Bone marrow biopsy showed mild cellular hyperplasia and increased megakaryocytes. Serologic evaluation for infectious diseases such as $\mathrm{HIV}, \mathrm{EBV}, \mathrm{CMV}, \mathrm{HCV}$ and $\mathrm{HBV}$ were negative. Serum Vitamin B12 levels were high (1900 $\mathrm{ng} / \mathrm{L}$ ). Chest radiography and abdominal ultrasound were unremarkable. Autoimmune markers (ANA and ds DNA) were negative. Immunophenotyping showed normal lymphocytes. Peripheral blood

${ }^{1}$ B.J.Wadia Hospital for Children and Research Centre, Acharya Donde Marg, Parel, Mumbai-400 012 , India

(Received on 9 September 2013: Accepted after revision on 25 October 2013) lymphocytes were analyzed by flow-cytometry for double negative T-cells using monoclonal antibodies against blood cell markers. The blood sample showed $5.2 \%$ of double negative cells. Lymph node biopsy also revealed reactive B-zone hyperplasia with presence of double negative $T$ cells. Hence, the patient was diagnosed to have ALPS on the basis of:

- Lymphadenopathy with splenomegaly

- Lymph node biopsy showing reactive B-zone hyperplasia with double negative $\mathrm{T}$ cells

- Peripheral blood showing raised circulating DNT cells

- Cytopenia

The patient fulfilled two required criteria and two supportive criteria, thus establishing the diagnosis of ALPS. He was treated with oral prednisolone $(1 \mathrm{mg} / \mathrm{kg} /$ day) for a period of two months with a significant decrease in the size of lymph nodes and an increase in platelet count on follow-up.

\section{Discussion}

To the best of our knowledge, very few cases of ALPS have been reported in South-East Asia, especially in the Indian subcontinent. The immune response to infectious agents results in the expansion of antigen-specific lymphocytes, some of which could become harmful to the host. The maintenance of proper homeostasis requires that lymphocyte expansion be appropriately balanced by lymphocyte elimination ${ }^{4}$. ALPS is a chronic, nonmalignant lymphoproliferative disorder caused by mutations in the genes that are involved in apoptosis. This impaired apoptosis leads to accumulation of lymphocytes causing lymphadenopathy, autoimmune phenomena and a high risk of developing malignant lymphomas. Most of the patients manifest between six months to 18 years. The most common autoimmune disorder is immune thrombocytopenic purpura (ITP) and haemolytic anaemia. There is also accumulation of phenotypically normal CD3+, CD4-, CD8- T cells (CD3+ DNT) ${ }^{5}$ Autosomal recessive and dominant mutations have been described $^{6}$. The ALPS phenotype is associated with inherited mutations in the CD95 gene (ALPS Type Ia) or the CD95 ligand gene (ALPS Type Ib). In ALPS Type II, a more severe clinical phenotype is presumed to be caused by an undefined inherited 
gene defect in the absence of mutations in the CD95 or CD95 ligand genes ${ }^{3}$. ALPS must be suspected in children presenting with autoimmunity and lymphadenopathy. Investigations should include flow cytometric analysis of peripheral blood to look for CD3+ DNT cells and ideally a test for apoptosis. However, demonstration of defective antigen induced apoptosis in cultured activated lymphocytes in vitro requires substantial laboratory support and incurs a significant cost. There are no curative treatment modalities for this entity to date. Initial line of treatment for most patients has been steroids and immunoglobulins with varied responses. Alternative options with pyrimethamine-sulfadoxime and mycofenolate mofetil have shown good response rates $(100 \%$ clinical response in seven patients and $92 \%$ hematological response in 13 patients respectively $)^{7,8}$. Other modalities of immunomodulation with vincristine and Rituximab have also been tried. Bone marrow transplantation has been done successfully in two cases with severe, worsening clinical phenotype ${ }^{9}$. Recently, treatment with Sirolimus resulted in complete response in patients with ALPS ${ }^{10}$. The diagnostic criteria for ALPS are given below:

\section{Diagnostic Criteria for ALPS ${ }^{11}$}

\section{Required Features:}

- Chronic, non-malignant, non-infectious lymphadenopathy and/or splenomegaly lasting at least 6 months

- Elevated CD3+ CD4-/CD8- double-negative (DN) $\alpha / \beta$ T-cell receptor (TCR) T cells $(\geq 1.5 \%$ of total lymphocytes or $2.5 \%$ of $\mathrm{CD} 3+$ lymphocytes) with normal or elevated lymphocyte count

\section{Primary Accessory:}

- Lymphocyte apoptosis in 2 separate assays

- A somatic or germline pathogenic mutation in Fas, FasLG or CASP10

\section{Secondary Accessory:}

- An elevated plasma level of soluble FasL $(>200 \mathrm{pg} / \mathrm{mL}) /$ elevated plasma interleukin-10 levels $(>20 \mathrm{pg} / \mathrm{mL}) / \quad$ elevated plasma interleukin-18 levels $(>500 \mathrm{pg} / \mathrm{mL}) /$ elevated serum or plasma vitamin B12 levels $(>1500$ $\mathrm{ng} / \mathrm{L}$ )

- Typical immune-histochemical findings reviewed by an experienced haematopathologist

- Autoimmune cytopenia (haemolytic anemia, neutropenia, or thrombocytopenia) with an elevated immunoglobulin G level (polyclonal)

- Family history of a non-malignant, noninfectious lymphoproliferation with or without autoimmunity.
Definitive diagnosis of ALPS is based upon the presence of required criteria and one primary accessory criterion. Probable diagnosis is based upon the presence of required criteria and one secondary accessory criterion. ALPS should be suspected in all patients with lymphadenopathy, chronic hepatosplenomegaly and cytopenia.

\section{Acknowledgements}

The authors thank Dr. Mukesh Desai, Consultant Immuno-hematologist, BJWHC for helping in the diagnosis and Dr.Y K Amdekar, the Medical Director, BJWHC for permission to publish the case.

\section{References}

1. Clementi R, Dagna L, Dianzani U, Dupre L, Dianzani I, Ponzoni M, et al. Inherited perforin and Fas mutations in a patient with autoimmune lymphoproliferative syndrome and lymphoma. New England Journal of Medicine 2004; 351(14):1419-24. http://dx.doi.org/10.1056/NEJMoa041432

2. Aspinall AI, Pinto A, Auer IA, Bridges P, Luider J, Dimnik L, et al. Identification of new Fas mutations in a patient with autoimmune lymphoproliferative syndrome (ALPS) and eosinophilia. Blood cells, Molecules \& Diseases 1999; 25(3-4):227-38. http://dx.doi.org/10.1006/bcmd.1999.0248

3. Alvarado CS, Straus SE, Li S, Dale JK, Mann $\mathrm{K}$, Le A, et al. Autoimmune lymphoproliferative syndrome: A cause of chronic splenomegaly, lymphadenopathy, and cytopenias in children-Report on diagnosis and management of five patients. Pediatric Blood Cancer 2004; 43(2):164-9. http://dx.doi.org/10.1002/pbc.20079

4. Martin DA, Zheng L, Siegel RM, Huang B, Fisher GH, Wang $J$, et al. Defective CD95/APO-1/Fas signal complex formation in the human autoimmune lymphoproliferative syndrome, type Ia. Proceedings of the National Academy of Sciences USA 1999; 96(8):4552-7.

http://dx.doi.org/10.1073/pnas.96.8.4552

5. Worth A, Thrasher AJ, Gaspar HB. Autoimmune lymphoproliferative syndrome: molecular basis of disease and clinical phenotype. British Journal of Haematology 2006; 133: 124-40. http://dx.doi.org/10.1111/j.13652141.2006.059 93.x 
6. Fisher GH, Rosenberg FJ, Straus SE, Dale JK, Middleton LA, Lin AY, et al. Dominant interfering Fas gene mutations impair apoptosis in a human autoimmune lymphoproliferative syndrome. Cell 1995: 81: 935-46.

http://dx.doi.org/10.1016/00928674(95)90013$\underline{6}$

7. van der Werff, Ten Bosch J, Schotte P, Ferster A, Azzi N, Boehler T, et al. Reversion of autoimmune lymphoproliferative syndrome with an antimalarial drug: preliminary results of a clinical cohort study and molecular observations. British Journal of Haematology 2002; 117: 176-88

http://dx.doi.org/10.1046/j.13652141.2002.033 $\underline{57 . x}$

8. Rao VK DF, Dale JK, Davis J, Tretler J, Hurley JK,Fleisher T, et al. Use of mycophenolate mofetil for chronic, refractory immune cytopenias in children with autoimmune lymphoproliferative syndrome. British Journal of Haematology 2005; 129: 534-8.

http://dx.doi.org/10.1111/j.13652141.2005.054 $\underline{96 . x}$
9. Sleight BJ, Prasad VS, DeLaat C, Steele P, Ballard E, Arceci RJ, et al. Correction of autoimmune lymphoproliferative syndrome by bone marrow transplantation. Bone Marrow Transplant 1998; 22:375-80.

http://dx.doi.org/10.1038/sj.bmt.1701306

10. Teachey DT, Greiner R, Seif A, et al. Treatment with sirolimus results in complete responses in patients with autoimmune lymphoproliferative syndrome. British Journal of Haematology 2009; 145(1):101-6. http://dx.doi.org/10.1111/j.13652141.2009.075 $\underline{95 . x}$

11. Oliveira JB, Bleesing JJ, Dianzani U, Fleisher TA, Jaffe ES, Lenardo MJ, et al. Revised diagnostic criteria and classification for the autoimmune lymphoproliferative syndrome(ALPS): report from the $2009 \mathrm{NIH}$ International Workshop. Blood 2010; 116(14): e35-40.

http://dx.doi.org/10.1182/blood-201004280347 